\title{
U.S. Geological Survey Volcano Hazards Program: Assess, Forecast, Prepare, Engage
}

\section{At least 170 volcanoes in 12 States} and 2 territories have erupted in the past 12,000 years and have the potential to erupt again. Consequences of eruptions from U.S. volcanoes can extend far beyond the volcano's immediate area. Many aspects of our daily life are vulnerable to volcano hazards, including air travel, regional power generation and transmission infrastructure, interstate transportation, port facilities, communications infrastructure, and public health. The U.S. Geological Survey has the Federal responsibility to issue timely warnings of potential volcanic activity to the affected populace and civil authorities. The Volcano Hazards Program (VHP) is funded to carry out that mission and does so through a combination of volcano monitoring, shortterm warnings, research on how volcanoes work, and community education and outreach.

Every day, VHP scientists work to enhance public safety and minimize social and economic disruption from volcanic unrest across thousands of miles in the United States. We monitor the progress of lava flows and persistent gas issuing from Kîlauea volcano, which poses hazards to communities across the Hawaiian Islands. We provide forecasts of ashfall from dozens of persistently active volcanoes in Alaska's Aleutian Arc and work in coordination with the National Weather Service Volcanic Ash Advisory Centers to track ash clouds that threaten communities and trans-Pacific aviation. We monitor activity to detect the earliest signs of reawakening at dangerous volcanoes such as Mount St. Helens, Mount Rainier, and

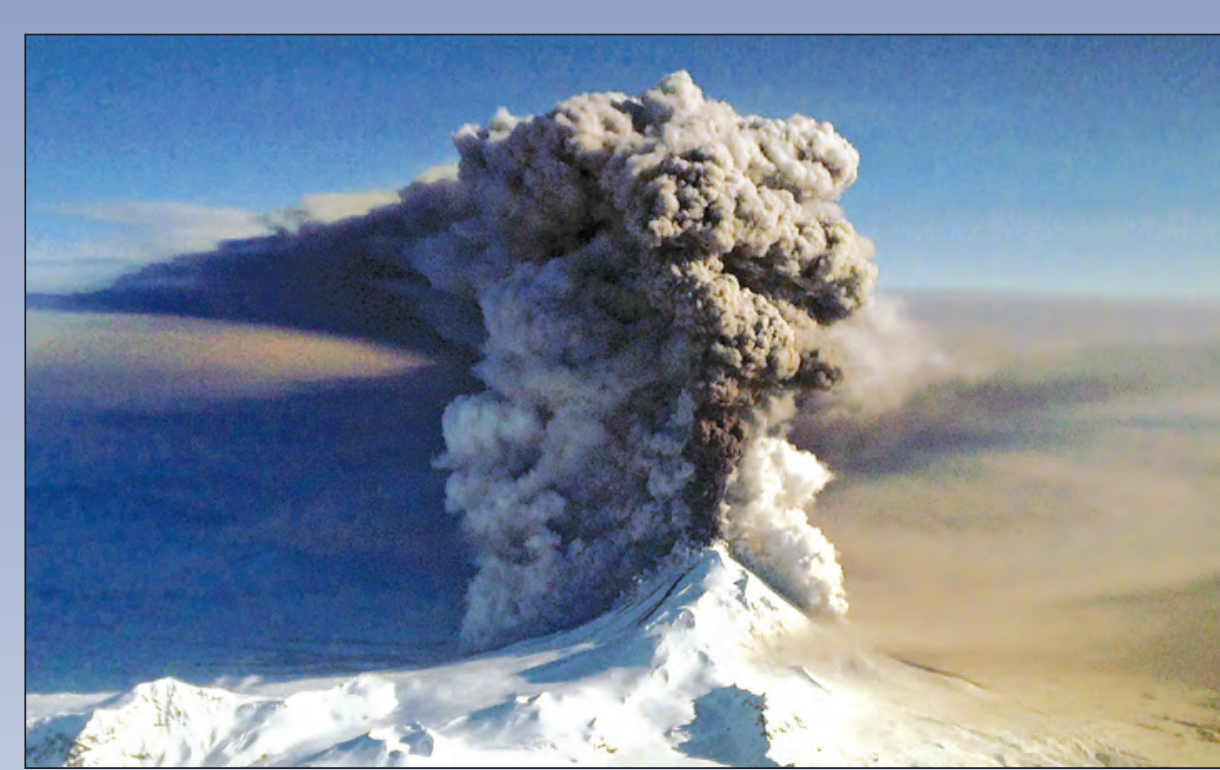

(Above) Pavlof volcano, on the southwestern end of the Alaska Peninsula, erupted in 2016. Impacts in March and May from volcanic ash hazards required cancellation of more than 100 commercial and passenger flights. Photograph taken at 20,000 feet on March 28, 2016, from Coast Guard 1713, a HC-130 H Hercules based at Air Station Kodiak, courtesy of Lieutenant Commander Nahshon Almandmoss. (Below) Lava flows from Kỉlauea Volcano encroached on the town of Pāhoa in November 2014, threatening infrastructure, businesses, and homes.

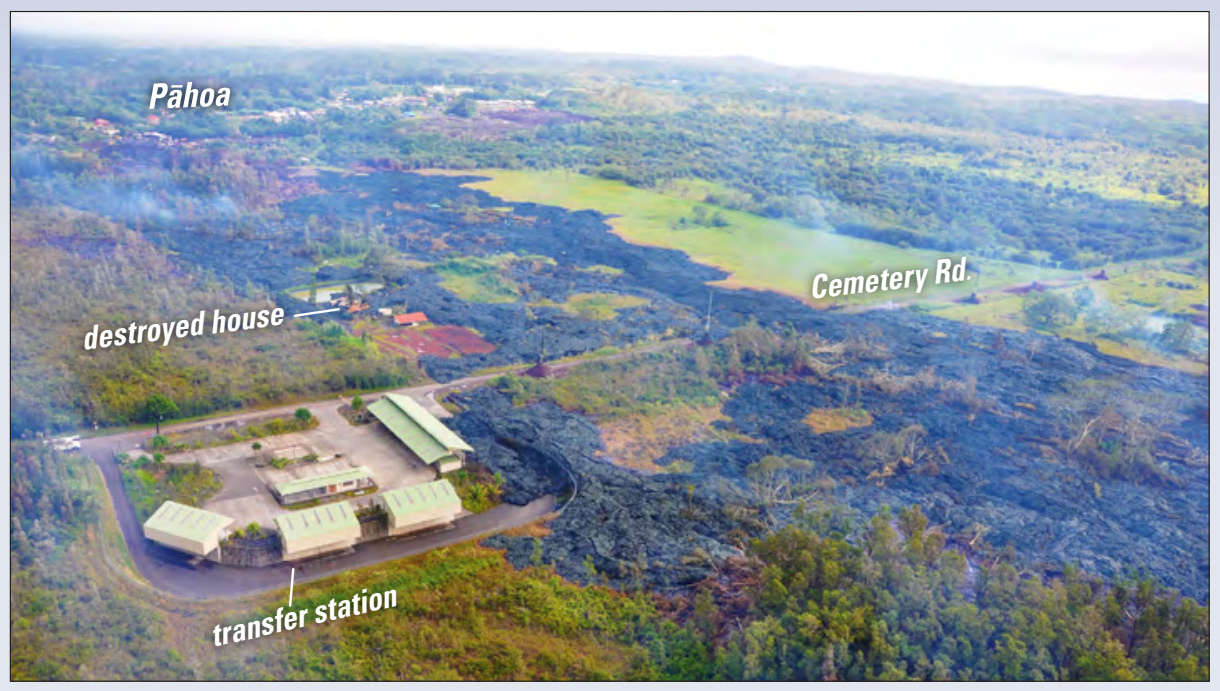

Mount Hood, which directly threaten more than 300,000 people in the Pacific Northwest. We conduct fundamental research to better understand some of the largest eruptions on Earth, such as those that occurred at Yellowstone-a still-active geothermal spectacle in the
mid-Continent. We ensure hazards are known and communicated for Mount Shasta, Long Valley Caldera, and a dozen other volcanoes in California that pose threats to populations, agriculture, and utility and transportation corridors. 

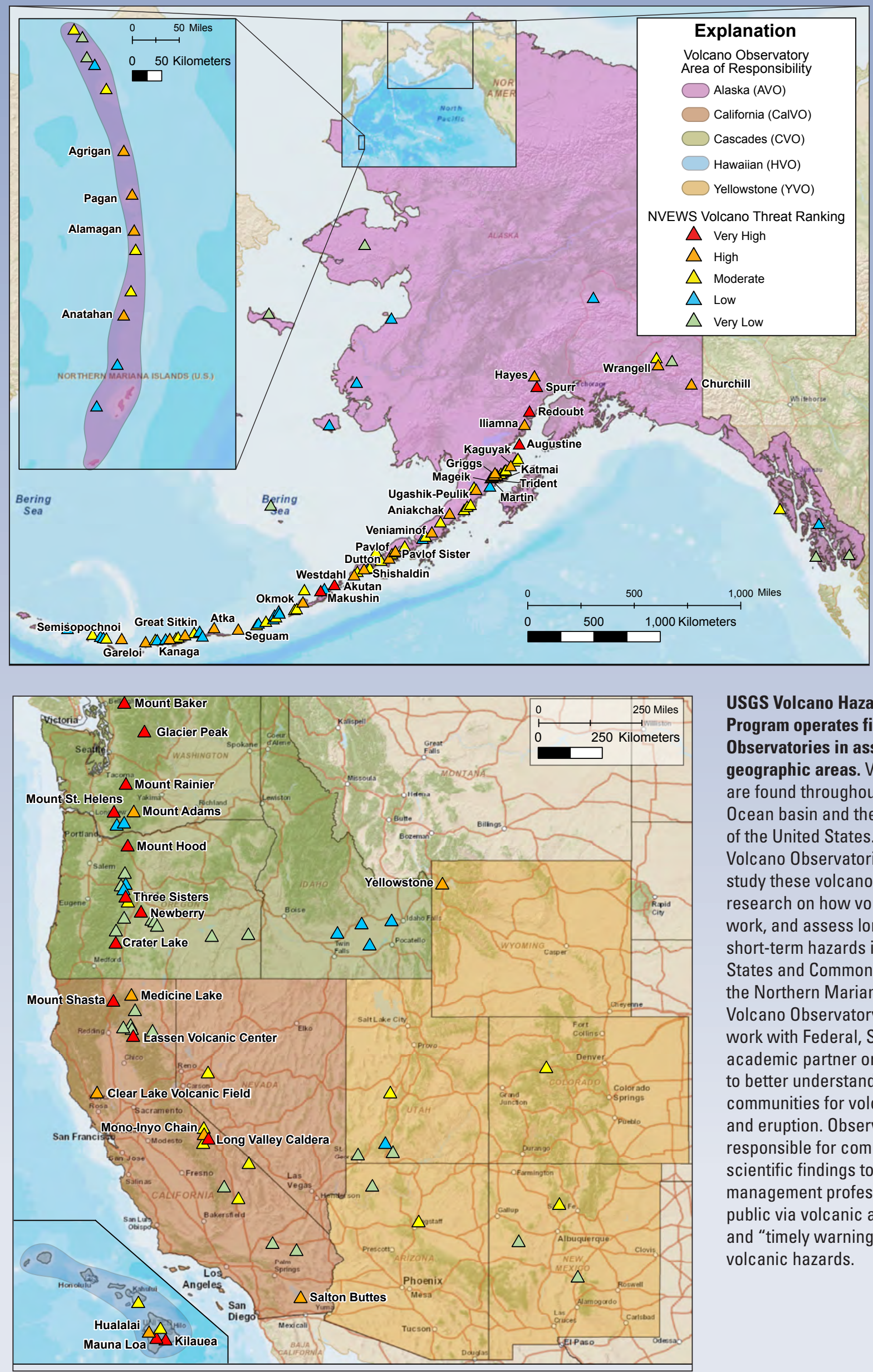

\section{USGS Volcano Hazards Program operates five Volcano Observatories in assigned geographic areas. Volcanoes} are found throughout the Pacific 0 cean basin and the western half of the United States. Staff at the Volcano Observatories monitor and study these volcanoes, conduct research on how volcanoes work, and assess long- and short-term hazards in the United States and Commonwealth of the Northern Mariana Islands. Volcano Observatory scientists work with Federal, State, local, and academic partner organizations to better understand and prepare communities for volcanic unrest and eruption. Observatories are responsible for communicating scientific findings to emergencymanagement professionals and the public via volcanic activity alerts and "timely warnings" of potential volcanic hazards. 


\section{National Volcano Early Warning System Ensures Volcanoes are Appropriately Monitored}

The National Volcano Early Warning System (NVEWS) is an ongoing national effort by the VHP and its affiliated partners to ensure that all U.S. volcanoes are monitored at levels matching the threats that they pose.

VHP scientists recognize that roughly one-half of the nation's 170 young volcanoes are potentially hazardous because of the manner in which they erupt and the presence of large at-risk communities and infrastructure downwind and downstream. Many of these volcanoes have insufficient monitoring systems or outdated equipment. The NVEWS plan ranks the volcanoes by threat level and prioritizes needs for upgraded monitoring networks so that hazardous volcanoes can be well understood in advance of reawakening. Adequate monitoring ensures that if communities and infrastructure are in harm's way, we will be able to deliver early and accurate notifications of developing hazards so that proper actions can be taken to save lives and property.

\section{Decision-makers Receive Rapid Notifications and Information Based on Research and Monitoring}

Active volcanoes are complex natural systems that operate at extremely high temperatures and pressures. They originate deep within the Earth and dynamically evolve as magma migrates to the surface. Understanding volcanic behavior requires the focus of multiple scientific disciplines. Scientists scrutinize signals such as small magnitude earthquakes, swelling of the ground, and rates and compositions of gas and water discharge. They interpret these signals while considering current knowledge about how volcanoes behave, the history of volcanic activity, and the geologic structure of nearby mountains and tectonic plates.

\section{Fundamental Research Helps Forecast Future Hazard Potential}

Fundamental research of volcanic processes before, during, and after eruptions allows scientists to understand volcano behavior and to forecast how eruptions might impact communities and ecosystems. VHP scientists conduct extensive field investigations, perform laboratory analyses, and develop physics-based process models. Together, these fundamental research activities help us understand events in past eruptions and develop new hypotheses about the inner workings of volcanoes. Research results improve eruption forecast accuracy and our predictions of the paths taken by destructive lava flows, landslides, lahars, and ash. They also form the basis for formal volcanic hazard assessments, guidance provided to emergency officials, and prioritization of volcano monitoring needs. VHP research is published in more than 100 scientific articles annually, and it is recognized and applied globally.

\section{Monitoring Networks Deliver Critical Information}

VHP scientists track volcanic activity by installing networks of sensitive instruments that continuously record the earthquakes, ground motion, and chemical changes that herald the onset of volcanic unrest. When deployed in periods of volcanic quiet, we learn a volcano's normal behavior. Therefore, when signals shift away from normal, we are able to more accurately detect signs of reawakening. Monitoring data also help us to evaluate whether a volcanic eruption is building up or calming down and to identify how explosive or hazardous an eruption might be. By relaying this information to authorities, VHP scientists provide guidance and important lead-time for successful evacuations, closures, and other mitigation actions.
Hazard Assessments Inform Planning, Preparedness, and Mitigation Decisions

Volcanic eruption hazards are numerous and widespread. Wind-blown ash and volcanic gases can paralyze National airspace, disrupt power grids, and trouble population centers thousands of miles downwind for days or more. Lahars (volcanic mudflows), floods, and high sedimentation rates can inundate communities and sever critical transportation corridors downstream. Lava and pyroclastic flows (avalanches of hot rock and gases) can devastate nearby areas downslope from volcanic vents.

To mitigate volcanic hazards, VHP scientists develop long- and short-term volcano hazards assessments. Long-term assessments combine known eruptive histories with computational models of hazards to identify areas at risk. These assessments are released as highresolution hazards-zonation maps with accompanying explanations. Long-term assessments form the basis for designing effective monitoring networks and guide local authorities in developing land-use and emergency preparedness plans. During an eruption, VHP scientists use long-term hazards assessments as a foundation for building day-today scenarios of potential eruption progress called short-term assessments. These products incorporate real-time monitoring data with hazards models based on current conditions

\section{Practicing Preparedness and Eruption Response Promotes Community Resilience}

The VHP works with Federal, State, and local officials to increase awareness of volcanic hazards and to help mitigate their effects. It is impossible to prevent a volcanic eruption from occurring, but impacts to communities are dramatically reduced when people know how to prepare for eruptions and where to get guidance during volcanic unrest. VHP personnel prepare educational materials and organize in-person training events specifically tailored to the needs of people at risk, emergency managers, and first responders. 
Partnerships between VHP staff and emergency response professionals strengthen coordination and communication during a volcanic crisis. Inter-agency groups develop and exercise emergency coordination plans together, well ahead of volcanic unrest. Under the guidance of the Department of Homeland Security's National Incident Management System, VHP staff work regularly with emergency managers to identify and to practice the roles they will assume during a crisis.

\section{Volcano Disaster Assistance Program Aims to Avert Volcanic Disasters and Advance Science Diplomacy}

The Volcano Disaster Assistance Program (VDAP) is a cooperative partnership between the U.S. Geological Survey and the U.S. Agency for International Development Office of Foreign Disaster Assistance. VDAP staff

In the last 50 years, impacts from eruptions and persistent degassing of volcanoes in Alaska, Washington, Hawaii, and the Commonwealth of the Northern Mariana Islands have cost billions of dollars. Because of population growth and development near volcanoes, the next eruption in the United States could affect millions of people. The economic sectors that have been affected by volcanic unrest in the last $\mathbf{5 0}$ years include:

- Agriculture

- Aviation/Airports

- Energy production

- Fishing

- Housing

- Human health

- Port facilities

- Refineries

- Transportation/Rail and Road

- Water supply and quality work to reduce volcanic risk, primarily in developing nations with substantial volcano hazards, by invitation of the host country. They assist through three main activities: eruption response, training and technology transfer, and long-term assessment of in-country hazards. Since its formation in 1986, VDAP eruption responses have also helped protect U.S. strategic assets and critical infrastructure deployed overseas.

Scientific exchanges between the VDAP foreign and VHP domestic programs provide mutual benefits. VHP scientists assist with VDAP activities in foreign locations, including installation of monitoring systems, scientific research exchange, outreach, and interpretation of monitoring data to improve forecasting. Because VDAP is persistently engaged with active volcanic unrest and eruptions around the world, when domestic crises occur, VDAP staff members are able to provide global perspective and a breadth of eruption-response experience. The experience gained by VHP staff at active volcanoes overseas is invaluable for the interpretation of volcanic unrest and to aid domestic response activities.

\section{U.S. Geological Survey Volcano Hazards Program Keeps Watch to Ensure Safety}

Most of the 170 volcanoes within the borders of the United States and its territories will erupt again. For many people, the concern about future eruptions from their local volcanoes is diminished by a sense of everyday normalcy, the volcano's natural beauty, and uncertainties surrounding when the next eruption could occur. Yet, it is the duty of the VHP to remain vigilantlearning about past eruption histories and connecting them to potential hazards, working with authorities, and issuing necessary warnings in the interest of public safety.

\section{Volcano Hazards Program Communications Support National Disaster Preparedness}

\section{During a volcanic event, volcano-} hazard information must be communicated quickly and accurately. The VHP promotes situational awareness through specific objectives:

- Issues authoritative forecasts and status updates of volcanic activity via structured messages to the Federal Aviation Administration, National Weather Service, and state and local emergency management authorities.

- Investigates and rectifies reports of unrest and eruption that are false or misleading.

- Provides access to volcanic information and real-time data to the public via websites, social media, and subscription services.

- Participates in targeted volcanohazard education and planning activities. With this information, officials and the public can make informed decisions and take appropriate actions during a crisis.
Where to Find U.S. Volcano Information

Volcano Hazards Program Website: volcanoes.usgs.gov

Volcano Notification Service: volcanoes.usgs.gov/vns

U.S. Geological Survey Volcanoes Facebook: www.facebook.com/ USGSvolcanoes

\section{Authors:}

Wendy K. Stovall, Aleeza M. Wilkins, Charles W. Mandeville, and Carolyn L. Driedger

For more information:

U.S. Geological Survey,

12201 Sunrise Valley Dr., MS 905

Reston, VA 20192

http://volcanoes.usgs.gov/

Publishing support provided by the

U.S. Geological Survey,

Science Publishing Network,

Tacoma Publishing Service Center

ISSN 2327-6916 (print) ISSN 2327-6932 (online) http://dx.doi.org/10.3133/fs20163040 